\title{
Injectable gellan-gum/hydroxyapatite-based bilayered hydrogel composites for osteochondral tissue regeneration
}

\author{
D.R. Pereira a,b, R.F. Canadas ${ }^{a, b}$, J. Silva-Correia ${ }^{a, b}$, A. da Silva Morais ${ }^{a, b}$, M.B. Oliveira ${ }^{a, b}$, I.R. Dias ${ }^{a, b, d}$, \\ J.F. Mano ${ }^{a, b}$, A.P. Marques ${ }^{a, b, c}$, R.L. Reis ${ }^{a, b, c}$, J.M. Oliveira ${ }^{a, b, c, *}$

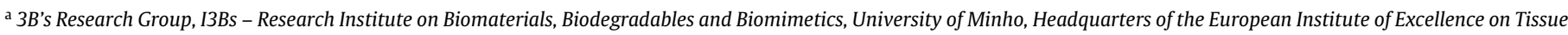 \\ Engineering and Regenerative Medicine, AvePark, Parque de Ciência e Tecnologia, Zona Industrial da Gandra, 4805-017 Barco, Guimarães, Portugal \\ ' ICVS/3B's - PT Government Associate Laboratory, Braga/Guimarães, Portugal \\ ' The Discoveries Centre for Regenerative and Precision Medicine, Headquarters at University of Minho, Avepark, 4805-017 Barco, Guimarães, Portugal \\ ${ }^{d}$ Department of Veterinary Sciences, University of Trás-os-Montes e Alto Douro, Quinta de Prados, P.0. Box 1013, 5001-801 Vila Real, Portugal
}

\section{A R T I C L E I N F O}

\section{Article history:}

Received 31 March 2018

Received in revised form 13 June 2018

Accepted 17 June 2018

\section{Keywords:}

Injectable biomaterials

Bilayered hydrogel composites

Gellan-gum

Hydroxyapatite

Osteochondral regeneration

Orthotopic knee model

\begin{abstract}
A B S T R A C T
Multilayer systems capable of simultaneous dual tissue formation are crucial for regeneration of the osteochondral (OC) unit. Despite the tremendous effort in the field there is still no widely accepted system that stands out in terms of superior OC regeneration. Herein, we developed bilayered hydrogel composites $(\mathrm{BHC})$ combining two structurally stratified layers fabricated from naturally derived and synthetic polymers, gellan-gum (GG) and hydroxyapatite (HAp), respectively. Two formulations were made from either low acyl GG (LAGG) alone or in combination with high acyl GG (HAGG) for the cartilage-like layer. Four bone-like layers were made of LAGG incorporating different ratios of hydroxyapatite (HAp). $\mathrm{BHC}$ were assembled in one single construct resulting in eight distinct bilayered constructs. Architectural observations by stereomicroscope and micro-CT $(\mu-\mathrm{CT})$ demonstrated a connected stratified structure with good ceramic dispersion within the bone-like layer. Swelling and degradation tests as well mechanical analyse showed a stable viscoelastic construct under dynamic forces. In-vitro studies by encapsulating rabbit's chondrocytes and osteoblasts in the respective layers showed the cytocompatibility of the BHC. Further studies comprising subcutaneous implantation in mice displayed a weak immune response after four weeks. OC orthotopic defects in the rabbit's knee were created and injected with the acellular BHC. OC tissue was regenerated four weeks after implantation as confirmed by cartilaginous and bony tissue formation assessed by histologic staining and $\mu$-CT analysis. The successful fabrication of injectable BHC and their in-vitro and in-vivo performance may be seen as advanced engineered platforms to treat the challenging $O C$ defects.
\end{abstract}

(c) 2018 Elsevier Ltd. All rights reserved.

\section{Introduction}

Osteochondral (OC) defects arise as a consequence of trauma, bone tumors, tissue resection, and metabolic diseases. When these affect the bone layer, a critical size lesion occurs and often leads to joint non-union. The OC unit is a multiphasic tissue comprising two distinct tissue types: the articular cartilage and the subchondral bone. Articular cartilage is a thin layer of soft anisotropic tissue responsible for protecting the surface of bones by reducing

\footnotetext{
* Corresponding author at: 3B's Research Group, I3Bs - Research Institute on Biomaterials, Biodegradables and Biomimetics, University of Minho, Headquarters of the European Institute of Excellence on Tissue Engineering and Regenerative Medicine, AvePark, Parque de Ciência e Tecnologia, Zona Industrial da Gandra, 4805017 Barco, Guimarães, Portugal.

E-mail address: miguel.oliveira@i3bs.uminho.pt (J.M. Oliveira).
}

friction and facilitating joint movement and shock-absorbance, while the subchondral bone fulfils a crucial role in mechanical support [1]. The avascular nature, unique chemical and cellular composition make hyaline cartilage difficult to regenerate in lesions that exceed a critical size [2]. Although loose tissue forms during cartilage healing [3], the degradation of the repaired tissue, cartilage dehydration and tissue thinning contribute to the progression of the lesion into deeper regions of the subchondral bone [4].

A wide range of clinical approaches has been exploited as primary/secondary treatments for managing a full-thickness chondral defect. Autograft transplantation [5] and bone marrow stimulation techniques such as microfracture [6], and subchondral drilling [7] are the surgical procedures most often employed to treat lesions classified from grade II to IV by the Outerbridge classification [8-11]. Cell-based techniques such as autologous chondrocyte implantation (ACI) [12] and matrix-associated 
autologous chondrocyte transplantation (MACT) are the most recently developed strategies with good clinical outcomes [13]. The new MACT approach offers great advantages over others [14] when treating young patients ( $<45$ years), although the ideal longterm strategies are far from being achieved. Acellular strategies such as the use of biomaterials that induce cell recruitment from the synovial membrane have been proposed to treat cartilage lesions [2]. The main drawback of current clinical approaches results in cartilage repair rather than regeneration. Fissures on the hyaline cartilage post-surgery may also allow synovium herniation into the subchondral osteoid causing pain and discomfort [15].

Multiphasic tissue engineering approaches combining cells, scaffolds and biomolecules may be seen as advanced platforms [16]. Thus, the focus should no longer be solely on hyaline cartilage regeneration [17]. The cartilage-bone interface for controlling total joint homeostasis presents anatomical features crucial to achieve functional regeneration of the OC unit [18]. Recently, a considerable number of comprehensive studies have focused on multiphasic/graded systems addressing the different OC tissues [19]. Oliveira et al. [20] developed a hydroxyapatite/chitosan (HAp/CS) bilayered scaffold using an innovative method that combines sintering and freeze-drying techniques. Getgood et al. [21] used collagen-based bilayered scaffolds aiming to regenerate OC defects in goats. Currently, the use of injectable hydrogel systems has been attracting a great deal of interest for the treatment of OC defects as they can be tissue mimetic and are easily injected into the cavity lesion by minimally invasive procedures. Specifically, injectable systems can reduce the risks associated with surgery and the need for recurrent post-surgeries. Furthermore, by filling the entire defect size, hydrogels minimize synovium infiltration into the subchondral osteoid thereby preventing cyst formation. Injectable hydrogels [22-25] are also advantageous to engineer functional environments that allow cell encapsulation and support its function. For this reason, Gellan gum (GG) [26,27] has been proposed for engineering cartilage substitutes [28-30] and has already received a great deal of attention in in-vivo experiments $[30,31]$. It has also been reported [32] that blood-vessel ingrowth and re-innervation from the subchondral bone into articular cartilage is a major impediment to achieving tissue regeneration and for managing pain. Therefore, it is advantageous the use of non- or antiangiogenic biomaterials that prevent blood vessel ingrowths into the lesion site. Recently, Silva-Correia et al. [31] showed the ability of methacrylated Gellan gum (GGMA) as non-angiogenic biomaterial for potential use in the restoration of avascular tissues such as cartilage.

The present work aims to regenerate $O C$ tissue through injectable gellan-gum based bilayered hydrogel composites. This work first explored the fabrication of a bilayered GG/GG-HAp hydrogel composite (BHC) consisting of a cartilage-like and a bonelike layer able to be used as an injectable system. The BHC were characterised to evaluate the physicochemical and mechanical properties by means of microscopy, micro-CT $(\mu-\mathrm{CT})$, dynamic mechanical analysis (DMA) and swelling/degradation tests. Bioactivity tests by SBF sample immersion were performed with further analysis by scanning electron microscopy (SEM) and x-ray diffraction (XRD). Indirect contact studies were carried out using a cell line (L929) to test possible toxic effects of the BHC. To assess viability and proliferative rate, chondrocytes and osteoblasts were encapsulated within each respective layer. The BHC compatibility was tested for immune responses by subcutaneous implantation in a mice model. Afterwards, the in-vivo study focused on investigating the regeneration of cartilage and subchondral bone tissue in an OC orthotopic defect in rabbit's knee. Neo cartilage and subchondral bone formation was assessed by micro-computed tomography (Viva-CT) and histological imaging.

\section{Materials and methods}

Low acyl Gellan-gum (LAGG, Gelzan ${ }^{\mathrm{TM}} \mathrm{CM}$, $\mathrm{Mw}=1000000 \mathrm{~g} / \mathrm{mol}$ ) was obtained from Sigma-Aldrich (USA) and High acyl Gellan-gum (HAGG, KelcoGel LT100) was provided by $\mathrm{CP}$ Kelco. Unless otherwise stated, all the reagents were purchased from Sigma-Aldrich.

\subsection{Bilayered hydrogel fabrication}

\subsubsection{GG/GG-hydroxyapatite bilayered hydrogel composites}

Distinct bilayered hydrogel composites (BHC) were fabricated varying both cartilage and bone-like layers. In total, eight different BHC were fabricated as outlined in Table 1.

Cartilage-like layers were fabricated from a solution of only LAGG at $20 \mathrm{mg} / \mathrm{mL}$ and from a solution of LAGG-HAGG, prepared from LAGG $(10 \mathrm{mg} / \mathrm{mL})$ mixed with HAGG $(7.5 \mathrm{mg} / \mathrm{mL})$ in a ratio of 75:25 $(\mathrm{v} / \mathrm{v})$, respectively. The bone-like layers of BHC were fabricated from solutions of LAGG $(20 \mathrm{mg} / \mathrm{mL})$ reinforced with hydroxyapatite (HAp) [30]. HAp was incorporated in LAGG solutions in four different batches at ratios of 5, 10, 15 and 20\% (LAGG-HAp). All solutions were prepared in distilled water in a water-bath at $90^{\circ} \mathrm{C}$, with constant stirring, until completely dissolved. Silicone moulds with $7 \mathrm{~mm} \times 4 \mathrm{~mm}$ were used to construct the BHC. Both layers, cartilage and bone, were put one upon another with the bone-like layer being the first at the bottom of the mould and topped by the cartilage-like layer. Then, the constructs were covered with phosphate buffer saline solution (PBS) to promote ionic crosslinking of GGMA.

\subsection{Microstructure evaluation of the bilayered hydrogel composites}

The bilayered hydrogel composites (BHC) were observed using a stereo microscope (Stemi 1000 PG-HITECH; Zeiss) in order to evaluate the interface and cohesion between the cartilage and the bone-like layers. The microstructure of the BHC was qualitatively and quantitatively assessed by high-resolution X-ray microtomography $(\mu-C T)$. To perform the analysis, all specimens were freeze-dried prior to X-ray analysis. 3D reconstruction was performed after scanning. Data were acquired with a Skyscan 1072 scanner (Skyscan, Kontich, Belgium), with a pixel size of $8.5 \mu \mathrm{m}$ and an integration time of $1280 \mathrm{~ms}$. The X-ray source was set at $33 \mathrm{keV}$ and $197 \mu \mathrm{A}$. Approximately 300 projections were acquired over a rotation range of $180^{\circ}$, with a rotation step of $0.45^{\circ}$. Data sets were reconstructed using standardised cone-beam reconstruction software (NRecon 1.6.6.0, SkyScan). The output format for each sample was bitmap images. The set of images was reoriented with DataViewer (v1.4.4, SkyScan) to obtain all samples in the same axis. Representative data set of the slices was segmented into binary images with a dynamic threshold of 30-120 for the cartilage-like layer phase and 120-255 for the bone-like layer phase analysis (grey values). Then, the binary images were used for morphometric analysis (CT Analyser, v1.12.0.0 $0^{+}$, SkyScan) and to construct the three-dimensional (3D) models (CT Vox, 2.3.0 r810, SkyScan).

Table 1

Different composition of the bilayered hydrogel composites (BHC).

\begin{tabular}{lll}
\hline Bone like layer & \multicolumn{2}{l}{ Cartilage-like layer } \\
\cline { 2 - 3 } & LAGG & LAGG-HAGG \\
\hline LAGG-HAp 5\% & LAGG/LAGG-HAp 5\% & LAGG-HAGG/LGGA-HAp 5\% \\
LAGG-HAp 10\% & LAGG/LAGG-HAp 10\% & LAGG-HAGG/LAGG-HAp 10\% \\
LAGG-HAp 15\% & LAGG/LAGG-HAp 15\% & LAGG-HAGG/LAGG-HAp 15\% \\
LAGG-HAp 20\% & LAGG/LAGG-HAp 20\% & LAGG-HAGG/LAGG-HAp 20\% \\
\hline
\end{tabular}




\subsection{Mechanical tests of the bilayered hydrogel composites}

The mechanical performance concerning the viscoelastic properties of the bilayered hydrogel composites was assessed by dynamic mechanical analysis (DMA). The viscoelastic measurements were performed using a TRITEC8000B DMA equipped with the compressive mode from Triton Technology. DMA analysis was carried out on in all bilayered hydrogel composites with a cylindrical shape of around $7 \mathrm{~mm}$ diameter and $4 \mathrm{~mm}$ thickness at $37^{\circ} \mathrm{C}$. The different bilayered hydrogel composites were analysed by immersion into a PBS bath in a Teflon ${ }^{\mathbb{B}}$ reservoir. The geometry of the specimens was then measured, clamped in the DMA apparatus and immersed in the bath. After equilibration, the DMA spectra were acquired during a frequency scan between 0.1 and $10 \mathrm{~Hz}$. The experiments were performed under constant strain amplitude. A small preload was applied to each sample to ensure that the entire surface was under compression. For all bilayered hydrogel composites being tested, the distance between plates was kept the same. DMA analysis was performed in triplicate $(n=3)$ for each condition.

\subsection{Swelling and degradation studies}

Swelling and degradation studies were carried out in all BHC by immersing them in PBS solution, $\mathrm{pH} 7.4$, followed by incubation at $37^{\circ} \mathrm{C}, 60 \mathrm{RPM}$, up to 30 days. At day 3, 7, 14, 21 and 30, the swelling ratio and degradation of all bilayered hydrogel composites were calculated The degradation of the bilayered hydrogel composites was studied over a period of 30 days, soaking them in PBS in a water-bath at $37^{\circ} \mathrm{C}$.

The swelling capacity (A) and degradation by weight loss (B) of all bilayered hydrogel composites were calculated by means of the following equations:

Swelling capacity $(\%)=\frac{W_{s}-W_{i}}{W_{i}} \times 100$

Weight loss $(\%)=\frac{W_{d}-W_{i}}{W_{i}} \times 100$

where $W_{i}$ (weight of freeze-dried bilayered hydrogel composite after fabrication); $W_{s}$ (weight of wet bilayered hydrogel composite after swelling at each time point, and $W_{d}$ (weight of freeze-dried bilayered hydrogel composite after swelling at each time point).

\subsection{Bioactivity tests}

Specimens of all BHC were immersed in simulated body fluid (SBF) according to Kokubo's method [33], with ion concentrations as shown in Table 2.

The molar concentrations of SBF were intended to mimic the human blood plasma. The SBF solution was adjusted to $\mathrm{pH} 7.4$ by adding $1.0 \mathrm{mM}$ of $\mathrm{HCl}$ solution in a bath of ice to prevent precipitation of $\mathrm{CaCO}_{3}$ minerals. Each $\mathrm{BHC}(n=3)$ was placed inside sterile $50 \mathrm{~mL}$ polystyrene sterile falcon tubes hanging on a metal wire to avoid contact with walls to prevent ion precipitation. Falcon tubes were filled with $30 \mathrm{~mL}$ of SBF solution and transferred into an incubator shaker at $36.5^{\circ} \mathrm{C}$ for up to 30 days. At each time point, the specimens were thoroughly rinsed in distilled water and frozen at $-80^{\circ} \mathrm{C}$ prior to lyophilisation. To evaluate the surface morphology of BHC, images were taken by scanning electron microscopy (SEM/EDS, NanoSEM-FEI Nova 200, USA). Prior to the

Table 2

Ion concentration in simulated body fluid (SBF).

\begin{tabular}{lllllllll}
\hline Ions & $\mathrm{Na}^{+}$ & $\mathrm{K}^{+}$ & $\mathrm{Ca}^{2+}$ & $\mathrm{Mg}^{2+}$ & $\mathrm{Cl}^{-}$ & $\mathrm{HCO}_{3}{ }^{-}$ & $\mathrm{HPO}_{4}{ }^{2-}$ & $\mathrm{SO}_{4}{ }^{2-}$ \\
\hline Conc. mM & 142.0 & 5.0 & 2.5 & 1.5 & 147.8 & 4.2 & 1.0 & 0.5 \\
\hline
\end{tabular}

analysis of microstructure, freeze-dried specimens were mounted on aluminium stubs and gold sputtered using a Fisons Instruments Coater (Quorum/Polaron E6700, UK) with a current of $18 \mathrm{~mA}$ and coating time $120 \mathrm{~s}$. Crystallinity and phase content of the BHC after SBF immersion were investigated by X-ray diffractometry (Bruker D8 Discover, Germany) employing $\mathrm{Cu}-$ Ka radiation. Data were collected from 6 to 75 ( $2 \theta$ values), with a step size of 0.04 , and a counting time of 2 s/step.

\subsection{In-vitro cytotoxicity}

An immortalised mouse lung fibroblast cell line (L929) was purchased from the European Collection of Cell Cultures (ECACC). The cells were grown in monolayer in DMEM culture medium supplemented with $10 \%$ foetal bovine serum (FBS, heat-inactivated; Biochrom) and $1 \%$ antibiotic-antimocotic mixture (A/B, Invitrogen). Trypsin (0.25\% trypsin-EDTA solution; Sigma) was employed to passage cells. L929 cells were seeded at a density of $1 \times 10^{5}$ cells/well into a 48 -well plate and incubated at $37^{\circ} \mathrm{C}$ in a humidified atmosphere of $5 \% \mathrm{CO}_{2}$. The possible toxic effect of the $\mathrm{BHC}$ was assessed by an indirect cytotoxicity test according to ISO 10993$5: 2009$. The BHC were produced as aforementioned in section 2.1, under sterile conditions. A minimum of $4 \mathrm{~g}$ of each hydrogel was incubated for 24 hours in $20 \mathrm{~mL}$ of complete Dulbecco's modified Eagle's medium (DMEM; Sigma) in a thermostatic bath $\left(37^{\circ} \mathrm{C}\right)$ with constant shaking $(60 \mathrm{rpm})$ for extract retrieval. A latex rubber extract was used as positive control: cell death, and complete culture medium was used as negative control. The extracts were passed through a $0.22 \mu \mathrm{m}$ filter and placed in contact with the L929 cell monolayer. Cell response was assessed at 24 hours, 48 hours and 72 hours after the incubation period. CellTiter 96 One Solution Cell Proliferation Assay Kit (Promega) was put in contact with the cells as per the manufacturer's protocol. The optical density was measured at $490 \mathrm{~nm}$ in a microplate reader (Synergy HT, Bio-TeK Instruments).

\subsection{In-vitro functional evaluation of OC-derived cells}

Chondrocytes and osteoblasts were isolated by the explant method from New Zealand White Rabbit knees (6-week-old male). Osteochondral $(\mathrm{OC})$ tissue was separated into cartilage and bone tissue that were indifferently chopped into small pieces and placed into a 6 well-plate with culture media, DME F: 12 for chondrocytes and alpha-MEM for osteoblasts both supplemented with 10\% FBS and $1 \% \mathrm{~A} / \mathrm{B}$ solution. Tissues were kept for one week in culture and the medium was topped up every 3 days. Afterwards, the primary cells were sub-cultured and used at P3-4.

\subsubsection{Fabrication of the OC cell-laden cartilage and bone-like layers}

Chondrocytes within LAGG and LAGG-HAGG for the cartilagelike layer and osteoblasts within LAGG/LAGG-HAp (5, 10, 15 and $20 \%$ ) were prepared separately. Solutions of both cartilage-like and bone-like layer were prepared as mentioned in Section 2.1.1 under sterile conditions. The chondrocytes were grown in monolayer in complete DMEM F:12 supplemented with $10 \%$ FBS and $1 \%$ $\mathrm{A} / \mathrm{B}$ and detached from the culture flasks after cells had reached $70-80 \%$ of confluence. A cell suspension of $1 \times 10^{6}$ cells $/ \mathrm{mL}$ was centrifuged at $1200 \mathrm{rpm}$ for $5 \mathrm{~min}$. Afterwards, the culture medium was completely aspirated and the cell pellet was re-suspended into the respective polymeric solution. Then, the mixture was poured into small petri dishes $(30 \mathrm{~mm}$ diameter) and covered with culture medium to promote ionic crosslinking. After $30 \mathrm{~min}$, small discs were cut with a $6 \mathrm{~mm}$ surgical punch. The discs were 
transferred into 48 well plates and incubated at $37^{\circ} \mathrm{C}$ in a humidified atmosphere of $5 \% \mathrm{CO}_{2}$ culture medium.

\subsubsection{Growth and proliferation of OC-derived cells}

The cell viability was investigated by using live/dead kit (Calcein-AM and propidium iodide, Molecular Probes ${ }^{\circledR}$; Life Technologies, Carlsbad, CA, USA) 3 days and 7 days of culturing time. Cell-laden hydrogels were washed with PBS and then incubated with Calcein-AM and propidium iodide solutions, both $1: 1000$, for 45 minutes. A reflected light microscope (Axio Imager Z1m, Zeiss, Jena, Germany) was used to observe the fluorescence emission.

Cell proliferative rate was quantified using the Quant-iT ${ }^{\circledR}$ PicoGreen dsDNA Assay Kit (Molecular Probes, Invitrogen Corporation, USA). Briefly, samples were collected at day 3 and at day 7 of culturing and washed twice with PBS. The cell-laden hydrogels were put in $1 \mathrm{~mL}$ of distilled water and subjected to heating at $70^{\circ} \mathrm{C}$ for one hour. Specimens were preserved at $-80^{\circ} \mathrm{C}$ until further analysis. At the time of analysis, specimens were thawed at room temperature and sonicated for $30 \mathrm{~min}$ at $40^{\circ} \mathrm{C}$ to induce complete cell membrane lysis. Pico-Green dsDNA Assay Kit was used following the manufacturer's instructions. Fluorescence readings were measured at an excitation wavelength of $485 / 20 \mathrm{~nm}$ and at an emission wavelength of $528 / 20 \mathrm{~nm}$, in a microplate reader (Synergy HT, BioTek Instruments, USA). The DNA concentration for each hydrogel was calculated using a standard curve with DNA concentrations ranging from 0 to $2 \mu \mathrm{g} / \mathrm{mL}$. Triplicates of all specimens were analysed.

\subsection{In-vivo studies}

All animal studies were performed according to the national guidelines and conducted in accordance with Portuguese legislation (Portaria 1005/92) and international standards on animal welfare as defined by the European Communities Council Directive (86/609/EEC).

\subsubsection{Subcutaneous implantation in mice}

Under surgical sterile conditions, two full thickness skin longitudinal incisions (about $1 \mathrm{~cm}$ ) containing the subcutis and the panniculus carnosus were made in the anterior and posterior dorsum of the mice. The animals were anesthetised by injection of: Ketamine $(25 \mathrm{mg} / \mathrm{kg})$ and medetomidine $(0.15 \mathrm{~mL} / \mathrm{kg})$ for anaesthesia; cephalexin ( $15 \mathrm{mg} / \mathrm{kg}$ ) as antibiotic; Bupivacaine, pethidine $(5-10 \mathrm{mg} / \mathrm{kg})$ as analgesia. Afterwards, the hair was removed at the implantation area, followed by $70 \%$ ethanol and iodine washings.

The in-vivo biocompatibility was evaluated after subcutaneous implantation of BHC, using a total of 6 mice (5-week-old mice Hsd:ICR (CD-1)). Cranial and lateral oriented subcutaneous pockets were created by blunt dissection, one on each side of the incision. The BHC LAGG/LAGG-HAp 20\% eres inserted into these pockets (4 constructs of the same material per animal), and the panniculus carnosus and the skin were carefully sutured. Mice were sacrificed at 2 weeks and 4 weeks post-operation and the $\mathrm{BCH}$ retrieved for further analysis.

2.8.1.1. Tissue processing and histological evaluation. At 2 and 4 weeks post-surgery, the mice were euthanised by injection of an overdose of pentobarbital sodium. The implanted BHC and the surrounding tissue were retrieved. Explants were fixed in $10 \%$ formalin, dehydrated through graded ethanol solutions and embedded in paraffin for further sectioning using a microtome (HM355S, Microm, Thermo Scientific). Sections of $5 \mu \mathrm{m}$ thickness were prepared and stained with hematoxylin and eosin (H\&E) and Masson's trichrome (MT) for histological evaluation. Sections were observed under a transmitted light Microscope (Zeiss, Germany).

\subsubsection{Orthotopic knee model}

Solutions of LAGG and LAGG-HAp 20\% were prepared and kept in two syringes in a water-bath at $40^{\circ} \mathrm{C}$ until injection. Three New Zealand white rabbits (9-11 weeks old, male) were used for creating OC defects by means of using an orthotopic knee model. Briefly, prior to surgery, animals were anesthetised by subcutaneous injection of a mixture of ketamine $(25 \mathrm{mg} / \mathrm{Kg})$ and medetomidine $(0.15 \mathrm{~mL} / \mathrm{Kg})$. General anesthesia was maintained by ventilator administration of isoflurane and oxygen. Animals were immobilised on their back and the hair from the legs was shaven followed by ethanol washings at $70 \%$ and iodine. Both knee joints in each animal were exposed through a medial parapatellar longitudinal incision. The synovial capsule was incised and the medial femoral condyle was exposed. Afterwards, an OC defect ( $5 \mathrm{~mm}$ diameter and $5 \mathrm{~mm}$ depth) was created in the centre of the condyle using a biopsy punch of $5.0 \mathrm{~mm}$ and dental drill. The defect was washed with saline solution prior to the first injection into the defect of LAGG-HAp $20 \%$ solution $(37.68 \mu \mathrm{L})$ followed by an administration of a second injection of LAGG solution $(25.12 \mu \mathrm{L})$. The defect dimensions were completely filled by the hydrogel. The crosslinking was made in situ by the presence of cations from previous washes with saline solution and by natural ionic fluids. Subsequently, the patella was repositioned, and capsule and muscle were sutured followed by skin suture.

2.8.2.1. Computed tomography. Rabbits were euthanised at 4 weeks post-surgery by administration of an overdose of pentobarbital sodium (i.v.). The knee joints were removed and scanned using Viva-CT 80 (Scanco Medical, Bassersdorf, Switzerland) after incubation with contrast agent to reveal articular surface topography and soft tissue features. Briefly, the explanted joints were immersed in a solution of $40 \%$ Hexabrix ${ }^{\circledR} 320$ (Guerbert, France)/60\% PBS $0.15 \mathrm{M}(\mathrm{v} / \mathrm{v})$ for $1 \mathrm{~h}$ at $37^{\circ} \mathrm{C}$ under gentle agitation. After incubation, the samples were patted dry and immediately transferred to the Viva-CT system for scanning. All scanning was performed at $70 \mathrm{kVp}, 114 \mu \mathrm{A}, 200 \mathrm{~ms}$ integration time, and a voxel size of $15.6 \mu \mathrm{m}$ with a $31.9 \mathrm{~mm}$ scanning tube. After scanning, the samples were immersed in 0.15 M PBS supplemented with protease inhibitors for $24 \mathrm{~h}$ at $4{ }^{\circ} \mathrm{C}$ to allow for desorption of the Hexabrix.

2.8.2.2. Tissue processing and histological evaluation. The surrounding tissue of the medial femoral condyle defect was retrieved en bloc. The medial femoral condyle was fixed in formalin $10 \%$ and further decalcified in formic acid for 3 weeks. Following this, the tissues were dehydrated through a graded series of ethanol solutions and embedded in paraffin. Longitudinal sections of $3 \mu \mathrm{m}$ thickness were taken with a microtome (Microm HM355S). Histological sections were stained with hematoxylin and eosin (H\&E), Safranin O/light green (Saf. O), and Masson's Trichrome (MT).

\subsection{Statistical analysis}

The data from in-vitro assays were analysed by one-way analysis of variance (ANOVA) and Bonferroni multiple-comparison test. The means and the standard deviations were reported in each graph and $p<0.05$ was considered as significantly different.

\section{Results}

\subsection{Microstructure and HAp distribution within the BHC}

Macroscopic images of the manufactured BHC revealed an excellent integrity of the interfacial system. Therefore, a whole single structure was developed showing a remarkable area of continuity at the interface integrating cartilage-like and bone-like layers (Fig. 1A). Higher magnification of BHC interface region with are 
shown in Fig. 1B. Different hydroxyapatite (HAp) ratios homogeneously dispersed within BHC were restricted to the bone-like layer. At the interface level there was an absence of crannies. Further BHC microstructure analyses performed by micro-CT $(\mu-C T)$ showed good combining characteristics of the two distinctive layers. Fig. 1C and D showed the incorporation of different ratios of HAp within the bone-like layer, LAGG-HAp (5, 10, 15 and 20\%) in combination with the respective cartilage-like layer of LAGG or LAGG/HAGG. The structures analysed by $\mu$-CT were threedimensionally (3D) reconstructed and it was ascertained that the amount of HAp was in accordance with theoretical values as well as with its distribution solely confined to the bone-like layer (Supplementary information, Fig. S1). For the cartilage-like layer (LAGG or LAGG-HAGG) presenting solely polysaccharide (GGbased), a threshold between 30 and 120 was applied to avoid the air noise (0-30). The HAp content for all different bone-like layers was traced applying a threshold between 120 and 255. The translucent lower layer (non-mineralised) was distinctly different from the HAp opaque upper layer (mineralised), cartilage-like and bone-like layer, respectively. Bone-like layer was denser than cartilage-like layer with a distinct composition: uniform and incremental distribution of HAp throughout the region.

\subsection{Mechanical and physico-chemical characterisation of BHC}

Variableness in the BHC was introduced in the change of their mechanical properties conferred by the two forms of GG (high and low acyl) used in respect to the cartilage-like layer and by the ceramic incorporation (HAp) in the bone-like layer. Likewise, the different ratios of HAp in the bone-like layer also led to distinctive mechanical properties. Dynamic mechanical analysis (DMA) was conducted to assess the elastic modulus $\left(E^{\prime}\right)$ as a function of the frequency. Fig. 2A and B showed the mechanical properties of all BHC, which present viscoelastic behaviour upon frequency increasing (from 0.1 to $10 \mathrm{~Hz}$ ).

The four different BHC made of LAGG/LAGG-HAp are seen in Fig. $1 \mathrm{~B}$ with $E^{\prime}$ ranging from 0.08 to $0.18 \mathrm{MPa}$ and for the LAGGHAGG/LAGG-HAp $E^{\prime}$ ranges from 0.12 to $0.16 \mathrm{MPa}$. Overall, the elastic modulus increases with increasing HAp content. Nevertheless, it can be observed that for BHC incorporating 20\% of HAp the $E^{\prime}$ is lower than that of the $15 \%$ HAp incorporation. The LAGGHAGG/LAGG-HAp with $15 \%$ and $20 \%$ HAp, where the curves overlap each other displayed an identical elastic modulus.

The swelling capacity of the BHC is shown in Fig. $2 \mathrm{C}$ and D for LAGG/LAGG-HAp and LAGG-HAGG/LAGG-HAp, respectively. An increasing profile in the water adsorption is seen up to day 7 remaining constant from that time period onwards. Differing from each other in respect to the cartilage-like layer, LAGG/LAGG-HAp formulations presented a water uptake capacity of around $3500 \%$ of their dry weight, while LAGG-HAGG/LAGG-HAp presented a water uptake of around $3000 \%$.

The degradation rate of the BHC is presented also in Fig. 2E and F. No formulations altered their weight significantly over 4 weeks under hydrolytic degradation. For LAGG/LAGG-HAp, the maximum weight loss of around $10 \%$ was seen for the formulation with higher HAp content and a weight loss of $5 \%$ was noted for formulation with less HAp amount. Conversely, LAGG-HAGG/LAGG-HAp presents the higher weight loss of $20 \%$ for the formulations with $5 \%$ HAp amount. The formulations of $10 \%, 15 \%$ and $20 \%$ HAp content present a weight loss of around $10 \%$ after 4 weeks.

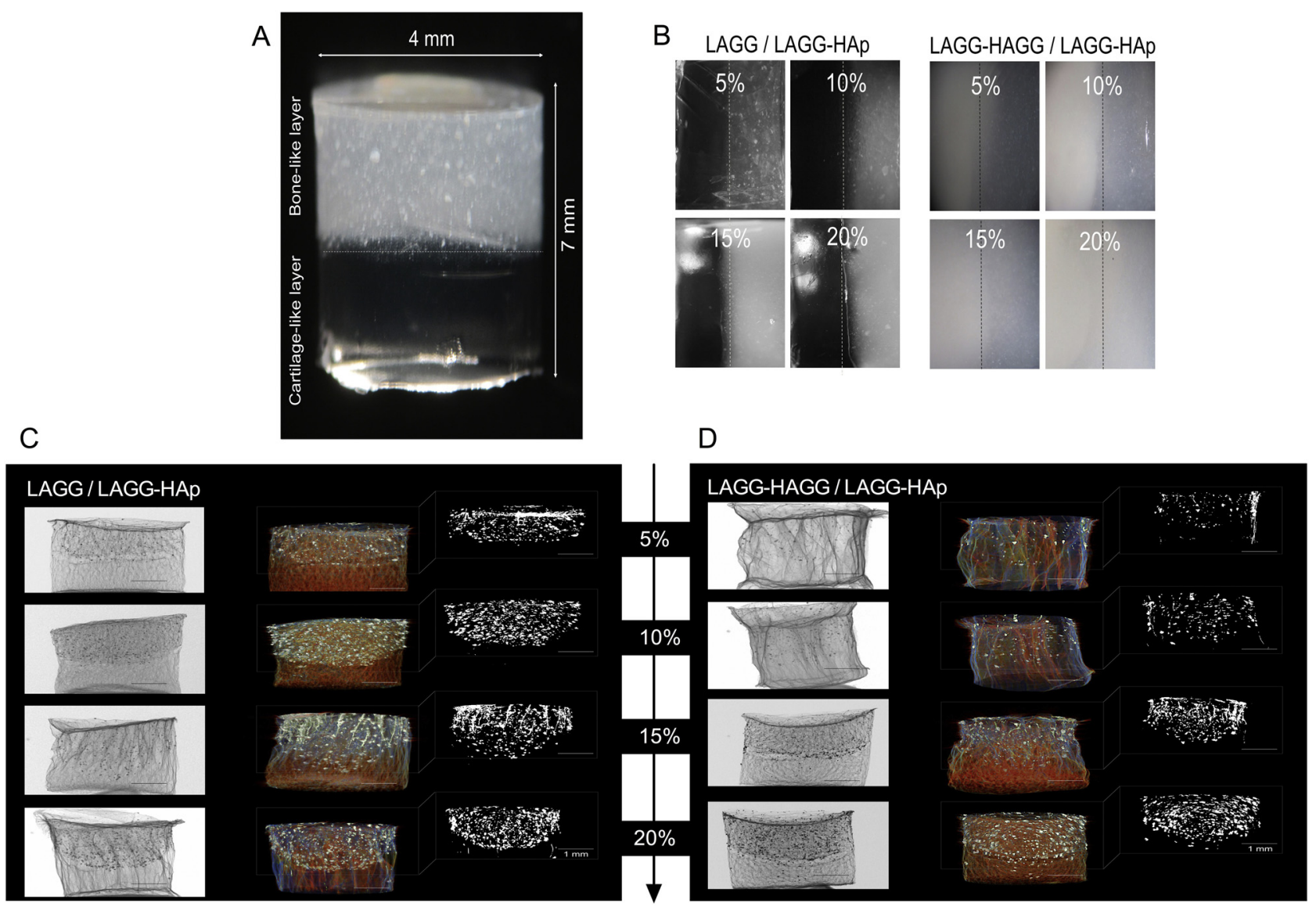

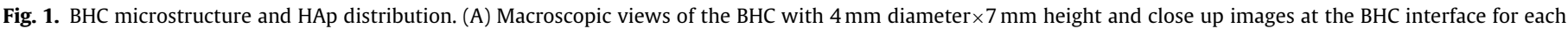
different BHC fabricated. $\mu$-CT analysis of the BHC for (C) LAGG/LAGG-HAp and (D) LAGG-HAGG/LAGG-HAp. Scale bar represents 1 mm. 

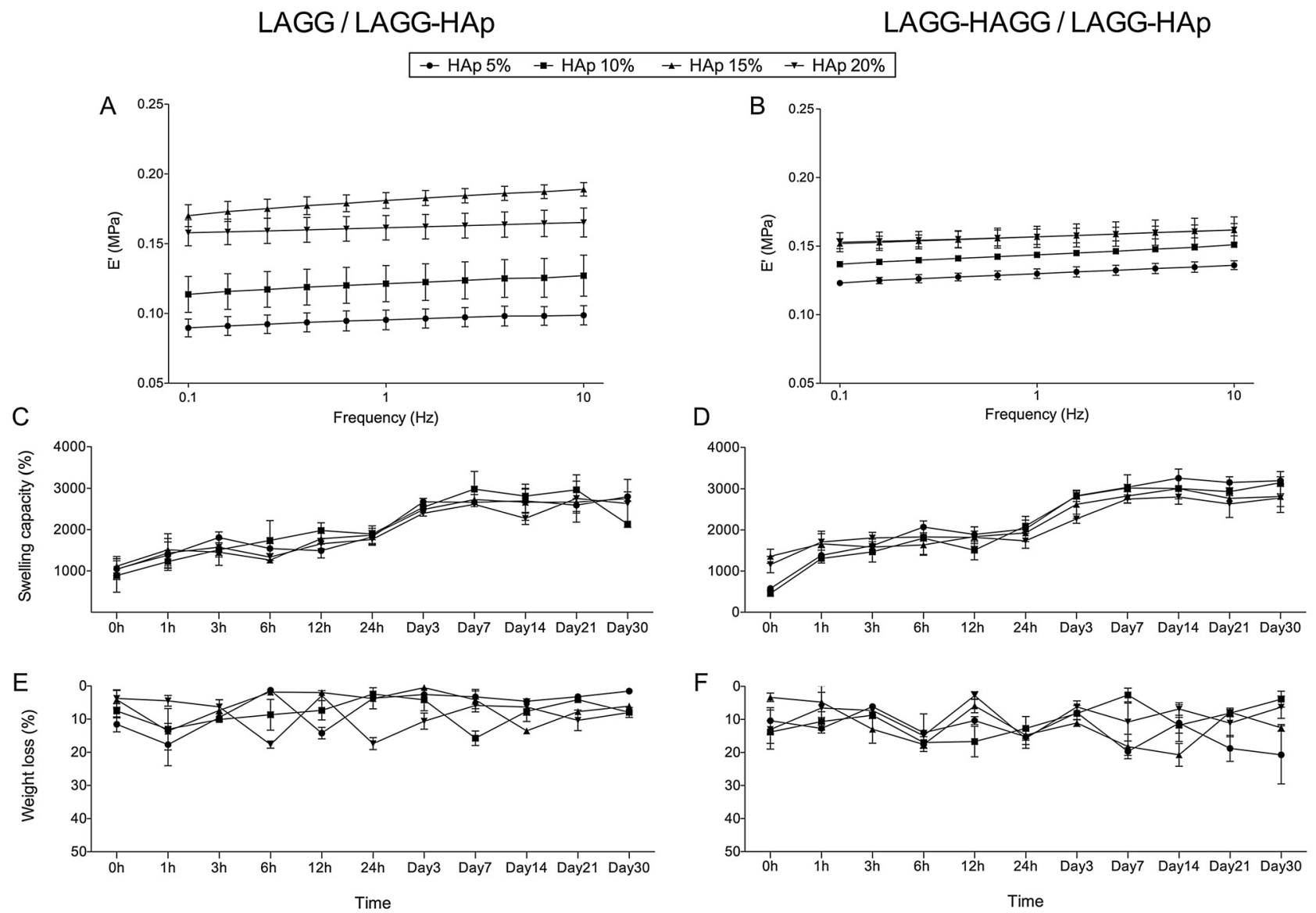

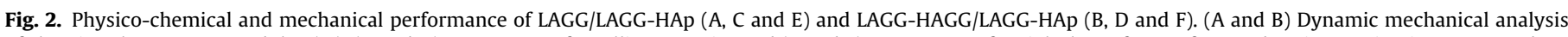

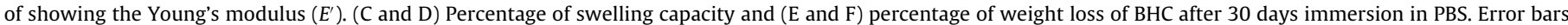
correspond to standard deviation.

\subsection{Bioactivity tests of the BHC}

To better understand the bioactive ability of the BHC to form apatite-like bioactive structures, analysis of SEM pictures and of XRD patterns of the BHC incubated for 30 days in SBF is shown in Fig. 3. The cartilage-like layer composed only by polysaccharide (LAGG or LAGG-HAGG) did not present cauliflower-like structures in SEM pictures (Fig. 3A) and further analysis of XRD patterns did not show the corresponding peaks of new apatite-like bioactive structures (data not shown). LAGG and LAGG-HAGG hydrogel formulations present smooth surfaces free of mineral deposits. In Fig. 3A, the layers incorporating different HAp amounts (5, 10, 15 and $20 \%$ ) revealed the formation of needle-like crystals, forming larger, round, cauliflower-like structures in the bone-like layer. XRD patterns after 30 days incubation in SBF (Fig. 3B) showed the formation of apatite in all formulations incorporating HAp, yet these are restricted to the bone-like layer. The new apatite-like structures are represented in the XRD patterns by the appearance of new peaks at $32^{\circ}, 33^{\circ}, 34^{\circ}, 40^{\circ}, 46.5^{\circ}$ and $49.5^{\circ}$ corresponding respectively to: (002), (211), (300), (202), (310), (22) and (213) planes of apatite [34]. The full coverage by an apatite-like layer at day 30 clearly seen for all formulations is clearly seen in Fig. 3C.

\subsection{In-vitro cytotoxicity}

To investigate the possible toxicity onto cells, all the BHC were incubated for $24 \mathrm{~h}$ in cultured media, at $37^{\circ} \mathrm{C}$. Afterwards, the extracts were placed in contact with L929 monolayer for further 3 days. Fig. 4A and B showed the metabolic activity of L929 cells until $72 \mathrm{~h}$ of culturing with extracts of LAGG/LAGG-HAp and LAGGHAA/LAGG-HAp, respectively. No cytotoxic effect was seen for all the BHC.

In regards to functional evaluation of the embedded OC-derived cells, in Fig. 4C and D, from a qualitative point of view, the chondrocytes within both LAGG and LAGG-HAGG formulations and osteoblasts within LAGG-HAp 5\% and LAGG-HAp 20\%, presented green fluorescence. The green signal is indicative of viable cells. The bone-like layer formulations, Fig. 4D, with osteoblasts embedded, showed a higher level of background in red due to the presence of HAp particles, which stain for red. Nevertheless, the viability indicator can be confirmed by DNA quantification. In Fig. 4E, chondrocytes present a significantly higher cell number for LAGG formulation than LAGG-HAGG, both at 3 days and 7 days of the culturing period. Regarding DNA quantification for BHC resembling bone-like layer, Fig. 4F presents LAGG-HAp 20\% with a significant higher proliferative rate than LAGG-HAp 5\%, at both time points 3 days and 7 days. Yet, both formulations presented a significant increase in cell number from day 3 to day 7 .

The outcomes from cytoxicity screening and the functional evaluation with OC-derived cells bring the formulation LAGG/LAGG-HAp 20\% upfront to be used in further acellular in-vivo subcutaneous implantation and orthotopic rabbit's knee model.

\subsection{In-vivo performance}

\subsubsection{Mice's subcutaneous implantation}

The in-vivo biocompatibility of the BHC (LAGG/LAGG-HAp 20\%) was evaluated by subcutaneous implantation in mice's dorsum. The 

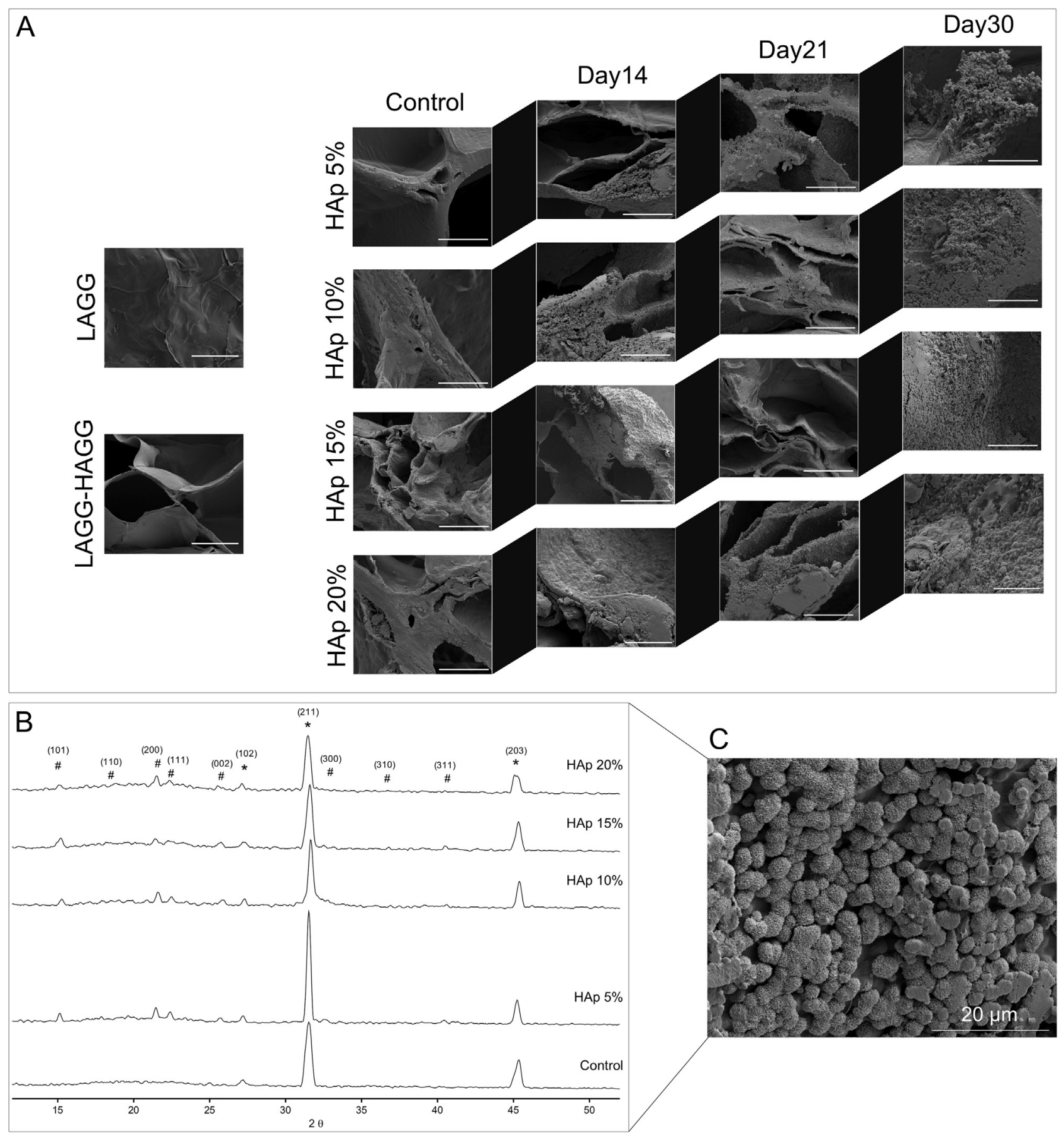

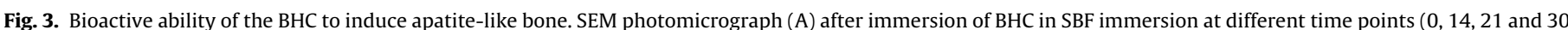

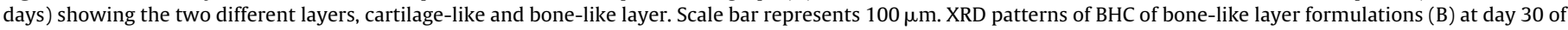
immersion in SBF, and representative SEM image (C) of apatite deposition at day 30.

BHC were explanted for macroscopic and histologic evaluation after 2 weeks and 4 weeks post-implantation. At 2 weeks post implantation (Fig. 5A), it was observed that a thin fibrous capsule formed around the BHC. At 4 weeks post implantation (Fig. 5B), a denser fibrous capsule formed totally enclosing the BHC. At 2 weeks and 4 weeks post implantation, the tissue was retrieved and processed for H\&E (Fig. 5A.i \& iii and B.i \& iii) and MT (Fig. 5A.ii \& iv and B.ii \& iv) staining. At 2 weeks and 4 weeks post implantation, histological images showed the natural tissue surrounding the BHC with good integration. At 4 weeks post implantation some cell infiltration were seen in the bone-like layer (arrows in Fig. 5B.i \& ii). The circular areas in the bone-like layers indicate topography of the hydrogel with HAp incorporation. In comparison with cartilagelike layer which presented a smooth topography, bone-like layer presented rougher topography with HAp particles embedded.

\subsubsection{Orthotopic rabbit's knee model}

The potential of the BHC to repair OC defects was evaluated by their implantation in an orthotopic knee defect in rabbits. Two critical size defects were induced per knee, anterior and posterior with $5 \mathrm{~mm}$ diameter and $6 \mathrm{~mm}$ depth as shown in Fig. 6A. 

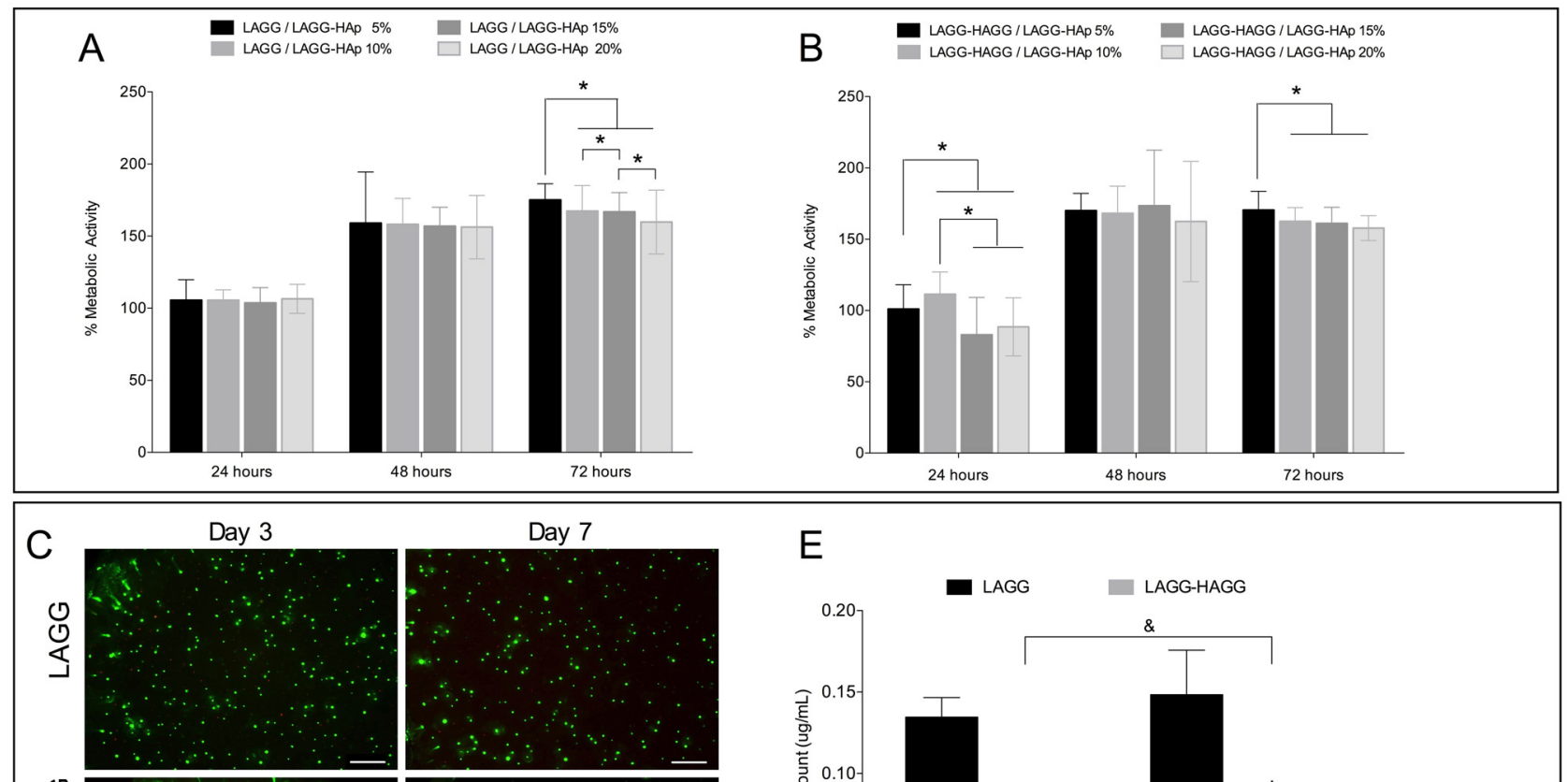
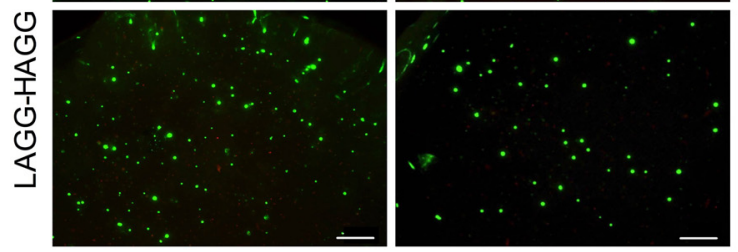

D
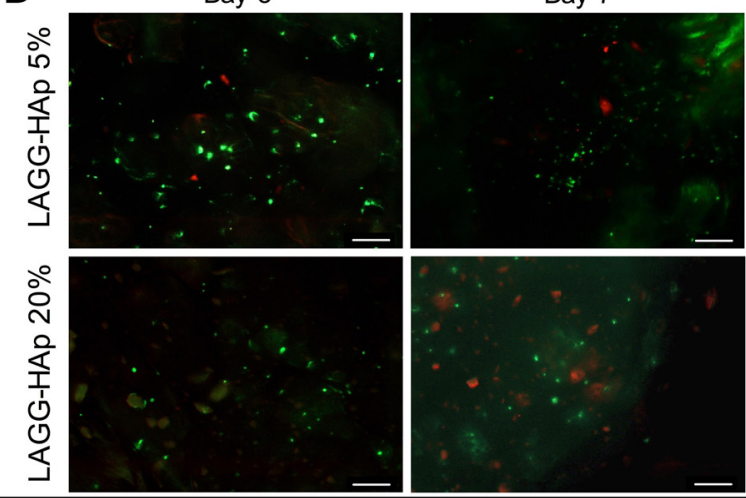

E

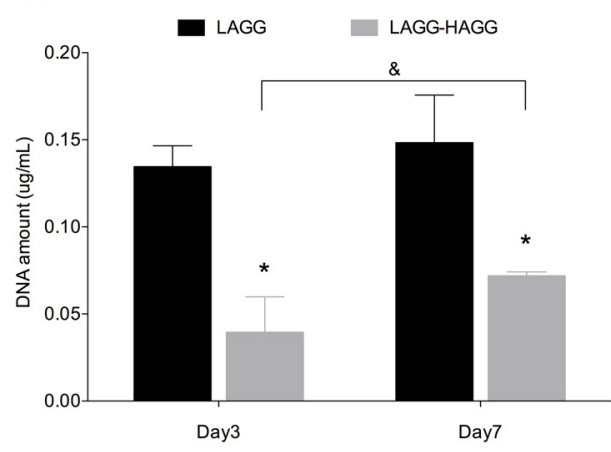

$\mathrm{F}$

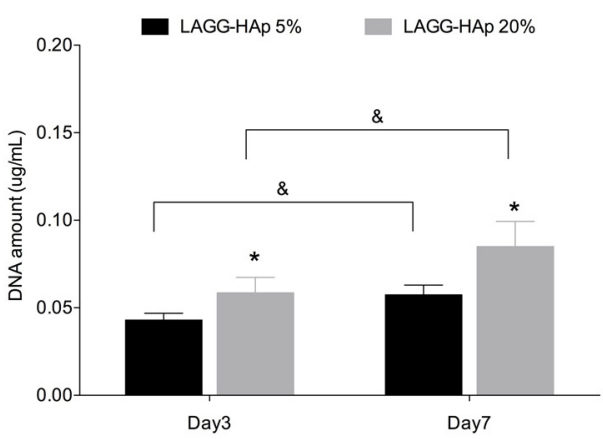

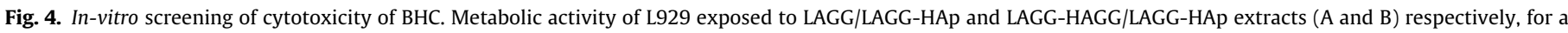

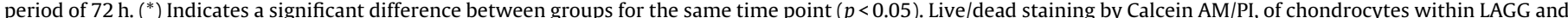

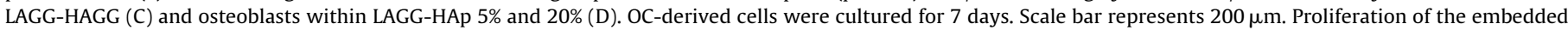

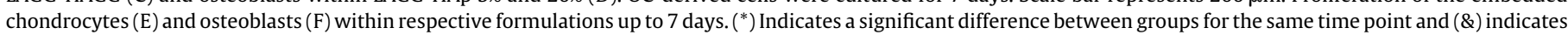
a significant difference between time points for the same formulation $(p<0.05)$.

The explanted knees (Supplementary information, Fig. S2) were analysed by Viva-CT. Representative Viva-CT images (Fig. 6B and C) of rabbit's knee showed subchondral bone ingrowth at the bottom domain (red) and cartilage repair at the top surface (green). The red signal was more pronounced in the BHC group (Fig. 6C) than in the control group (Fig. 6B). From Viva-CT data, the newly formed subchondral bone appears to be co-localised (red) with the bonelike layer in the BHC (Fig. 6C). The control group did not show any subchondral bone formation and a week green signal (cartilagelike) was seen on the top surface (Fig. 6B). In the other hand, for the $\mathrm{BHC}$ group an intensely green colour in the top surface (cartilagelike) and red colour at the bottom of the BHC (bone-like layer) is clearly evident.
Histological examinations (H\&E, MT and Saf. O) confirmed the formation of cartilage-like and underlying bone-like tissue. Fig. 6D and E shows representative histological Images 4 weeks post-surgery. For the Control group (Fig. 6D), neither cartilage as a uniform tissue or subchondral bone formation was seen in histological images. Moreover, there is no specific architecture of the newly formed tissue. It presents only loose tissue formation without any organisation and fulfilling the site defect from top to bottom (Fig. 6D). In Saf. O images at higher magnification (Fig. 6D.iv and D.v) is clearly seen the formation of loose tissue in both, cartilage-like and bone-like layers. The fissure within the defect presented loose tissue and is seen in all staining (H\&E and MT). Although the defect was filled with tissue, the newly formed tissue 


\section{2 weeks}

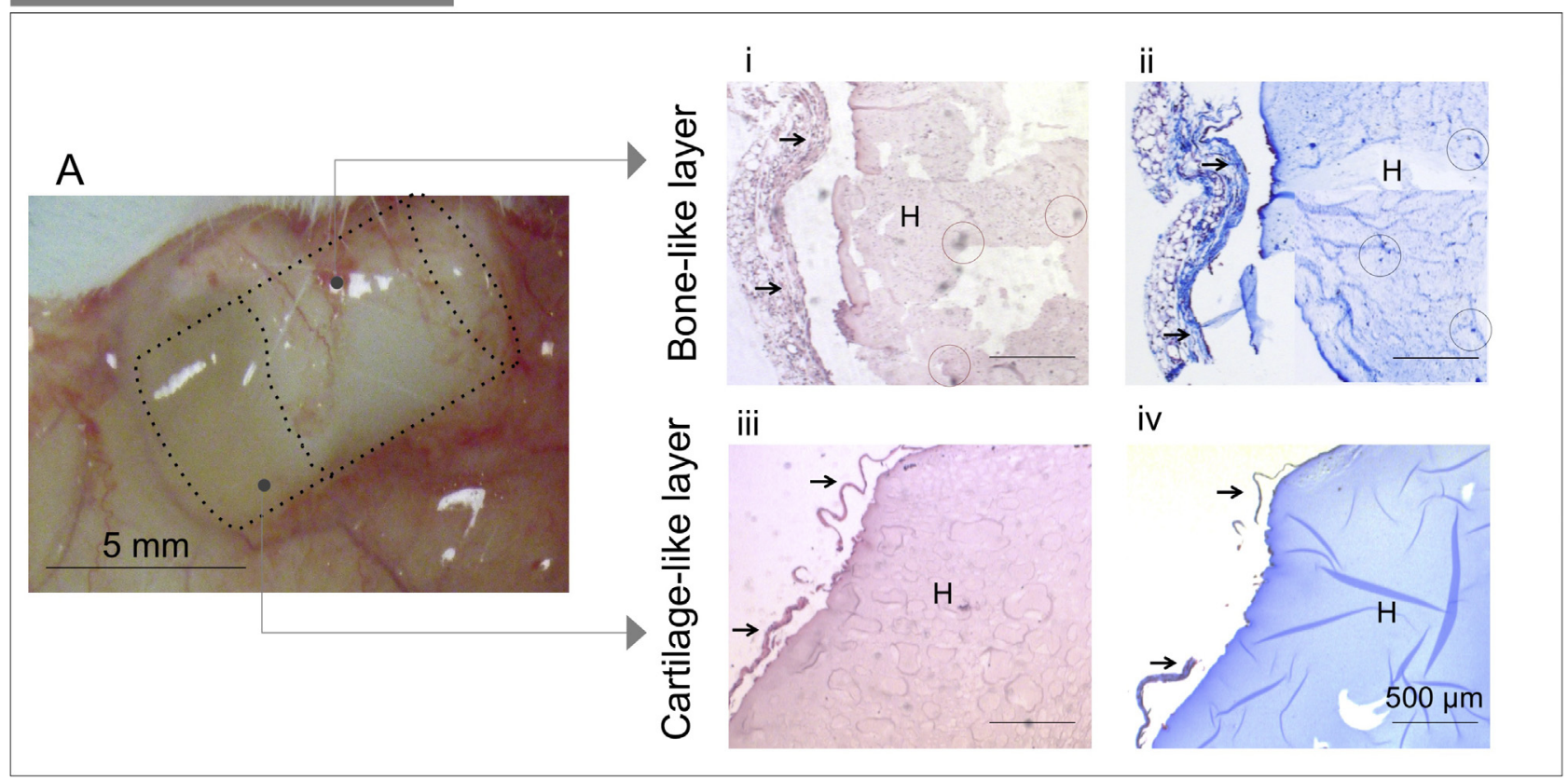

\section{4 weeks}

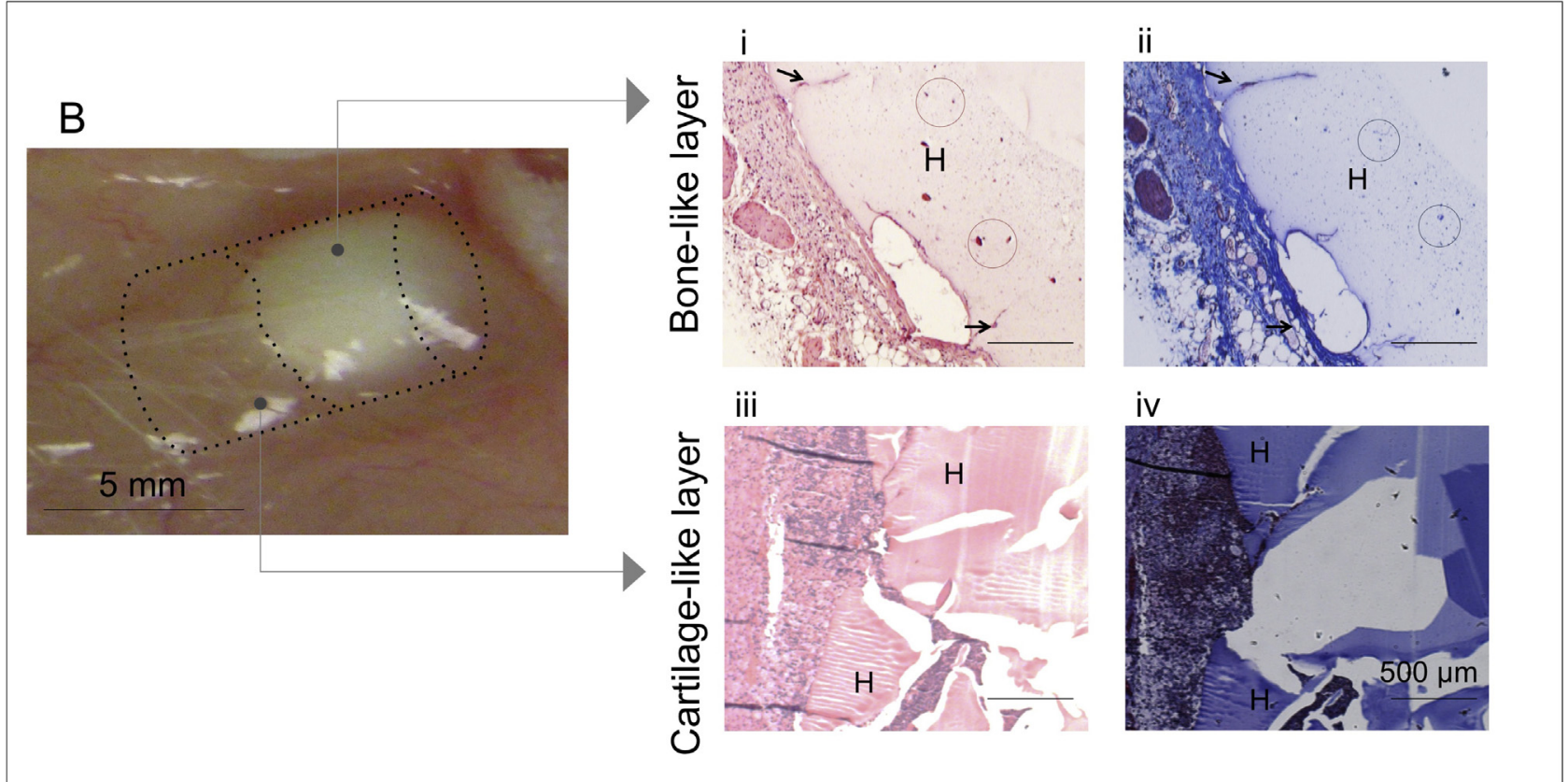

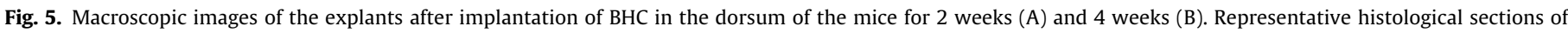

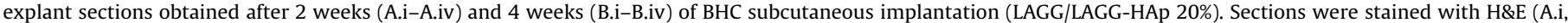
A.iii, B.i and B.iii) and MT (A.ii, A.iv, B.ii and B.iv). Abbreviations: H: hydrogel.

appears irregular with a disorganised structure for both cartilage (Fig. 6D.iv) and bone (Fig. 6D.v) regions. The cell arrangement in the new cartilage is more irregular than that in surrounding cartilage.

With regards to the BHC group, Fig. 6E revealed new tissue formed on the top surface gradually covering the surface of the defect with an intense pink colour on the edges (Fig. 6E.iv). The cartilage tissue on the surface covers only the top (Fig. 6E.ii), unlike the control group where cartilage ingrowth was seen inside of the site defect. The BHC group showed tissue-containing cells (Fig. 6E.iv) forming new cartilaginous tissue, yet restricted to the top layer in the surface. No signs of inflammation were seen in any of the explants and no collapse of adjacent tissues was noted in BHC group. 4 weeks after, the implanted BHC were partially degraded with some fragments retained in the defect site (indicated by ${ }^{*}$ ) 


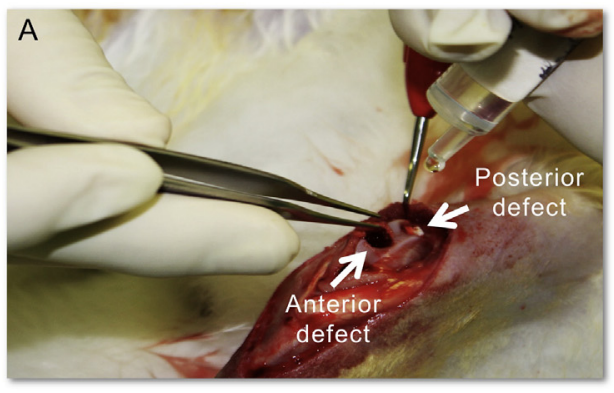

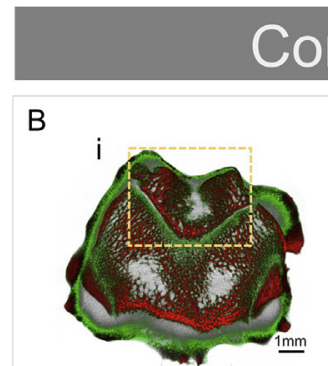

D

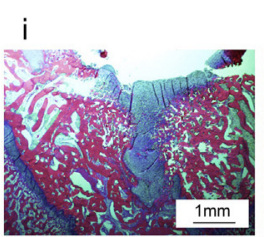

iv

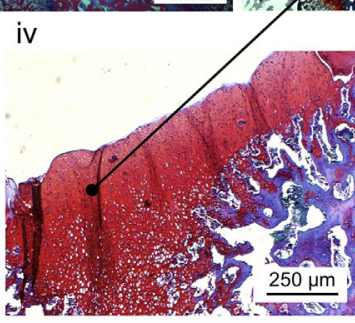

ii

ii

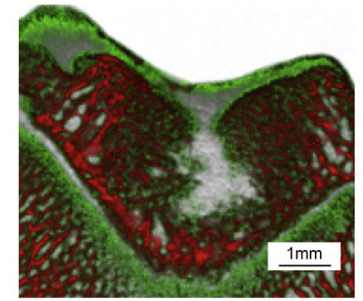

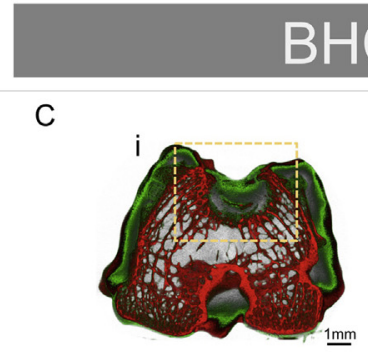

BHC group

ii

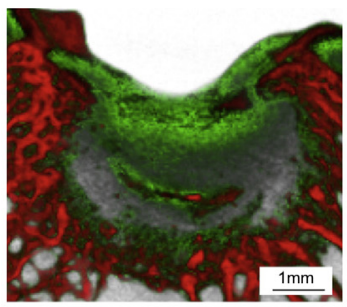

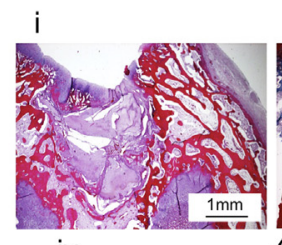

iv

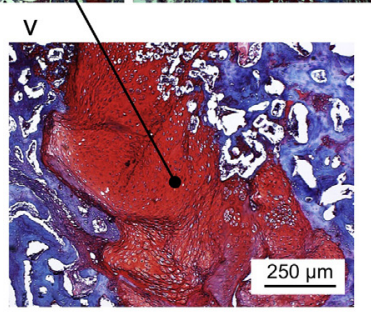

iii

5. 1 ii

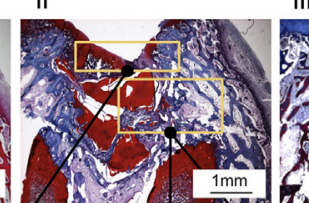

ii

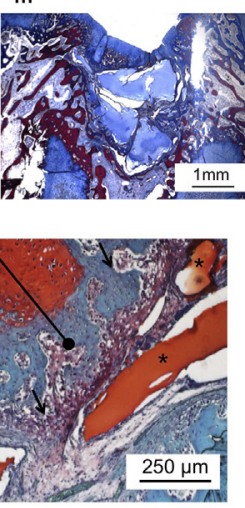

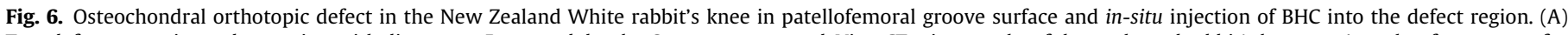

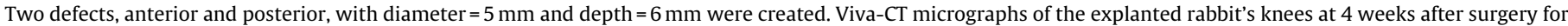

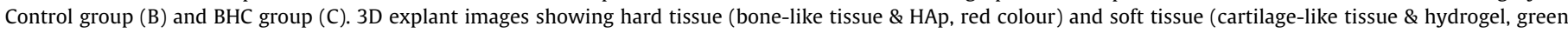

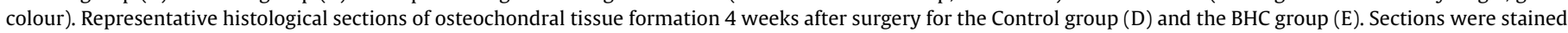

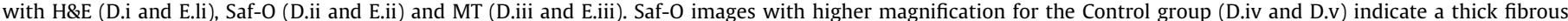

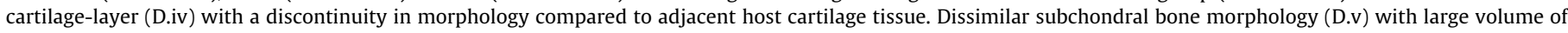

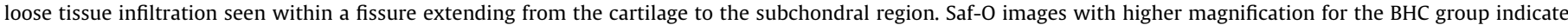

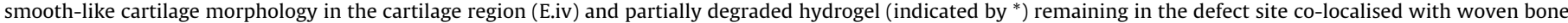
islets in the subchondral region (E.v).

yet well integrated with the adjacent tissues and with some cell infiltration and tissue forming in the subchondral region (Fig. 6E.v).

\section{Discussion}

An optimal functional construct with accurate physical, structural and biochemical cues will distinctly regenerate cartilage and bone in an OC defect. Recently, a large number of multiphasic/multilayered systems have followed a multi-directional biomimetic design to offer alternatives or to improve existing osteochondral (OC) substitutes [18,35,36]. The use of hydrogels is a very interesting approach since they are capable of mimicking the 3D natural tissue environment while filling the critical size defect [37-39]. Moreover, their similarity to natural ECM in terms of water-content, biodegradability and viscosity has been considered an advantage in tissue engineering strategies [40].
The present work aimed to develop bilayered hydrogel composites (BHC) based on previous work done in the group [20,36,41]. Herein, the designed BHC presented a very promising architecture and a biomimetic area restricted to the bone region. The proposed BHC presented good mechanical properties analogous to those of the OC tissues. Our study exploited a number of potential advantages in using GG-based biomaterials such as the unique viscoelastic property and injectability $[42,43]$. In addition, GG gelation occurs in cations presence which allows the tailoring of GG mechanical strength, elasticity, and degradation rate.

The simultaneous regeneration of cartilage and bone without functionally compromising any of the two dissimilar tissues are totally reliant on the multi-layered system's cohesion and functional integration $[18,19]$. Because the BHC design is the kernel of any OCTE, the construct possessed distinct regions for the formation of different functional tissues that were assembled together. 
Therefore, an interfacial region was formed and that was capable of combining and integrating both materials in a single stable unit. Moreover, the stability of such an interface was evaluated when subjected to dynamic mechanical analysis up to $10 \mathrm{~Hz}$ and did not undergo any break or form crevices afterwards.

OC-repairing hydrogel composites were not designed to perfectly match the mechanical properties of the tissue to be repaired but rather to serve as a temporary structure for new tissue formation [44]. The BHC constructs showed an improvement in the mechanical properties over those in previous work $[43,45]$ enabled by the assemble of the bilayered construct and by the HAp incorporation within the bone-like layer. HAp incorporation result in more suitable BHC to be applied as OC substitutes with better mechanical properties. GG-based hydrogels being exceptionally stable under physiological fluids due to the presence of ions did not present significant weight loss after 30 days immersion in PBS. Moreover, in the human body the presence of ions in the natural fluids, particularly calcium, can easily induce GG mechanical changes which in turn yield a higher GG crosslinking degree and thus higher $E^{\prime}$ [46]. The reinforcement of the bone-like layer with a ceramic compound such as HAp stimulated the mineral formation by its nucleating capacity. HAp is the main inorganic component in calcified hard tissues present in $65 \%$ in the interface region and $86 \%$ in the subchondral bone $[47,48]$. Thus, BHC with HAp restricted to the bone-like layer was strategically conceived to induce formation of $\mathrm{CaP}$ in the form of apatite as demonstrated by incubation in SBF $[49,50]$. However, it is crucial that the cartilage-like layer does not present a bioactive behavior, as this would compromise the regeneration of functional cartilage. Cartilage-like layers, LAGG or LAGG-HAGG, did not induce apatite formation on their surfaces in SBF immersion up to 30 days. In contrast, mineral deposits were further confirmed in the bone-like layer of the BHC as apatite-like structures. XRD patterns provided direct insights into mineral formation as a result of bioactive HAp incorporation. Hence, carboxyl group-containing organic polymers were able to induce apatite in $\mathrm{SBF}$ solution in the four different layers targeting bone-like layer (5, 10, 15 and $20 \%)$.

In respect to the cell studies, a first screening of possible toxic chemicals within BHC that could harm the cells was carried out and showed no deleterious effect over L929 cells. All cells cultured on BHC showed significantly increased metabolic activity over time. The statistical significances between groups are absolutely negligible as metabolic activity is very high (percentage calculated in relation to negative control). Afterwards, primary OC-derived were isolated and cells were embedded within each respective formulation; specifically rabbit's chondrocytes and osteoblasts, within cartilage-like and bone-like layers, respectively. Both type of cells were viable up to 7 days within the respective formulations. Cell proliferation was seen for the majority of the formulations. Specifically for the cartilage-like layer, LAGG presented a significantly higher number of cells whilst for bone-like layer the formulation LAGG-HAp $20 \%$ presented a significantly higher number of cells, up to 7 days in culture. Therefore, LAGG and LAGG-HAp 20\% were chosen as the best formulations that were able to maintain viability and allowed proliferation over time.

To ascertain the in-vivo biocompatibility of BHC, subcutaneous implantation was performed in nude mice. Despite the total integrity of BHC 2 weeks after subcutaneous implantation, minimum foreign body reaction was induced. After 4 weeks, BCH still remained in the site defect and the slow degradability of BHC is in line with the physico-chemical and mechanical evaluation. This suggests the superior in-vivo performance of BHC for balanced degradation while neo-tissue formation takes place and for the maintenance of mechanical forces. New-tissue formation and BHC degradation must act synergistically in a balanced manner prompting cell function and ECM formation. Newly formed connective tissue was clearly seen surrounding the periphery of the $\mathrm{BCH}$ with some cell infiltration in the bone-like layer 4 weeks after implantation.

The ultimate objective of this study was to determine whether the acellular BHC would be feasible for OC tissue regeneration. Commercially available MaioRegen ${ }^{\circledR}$ is a collagen $\mathrm{I} /$ nanohydroxyapatite scaffold used in OC defects to mimic chondral and $\mathrm{OC}$ anatomy, respectively. Besides showing trabecular bone ingrowth and fibrocartilaginous tissue formation about, there are reports of problems with fixation due to the exacerbated aggravated swelling when it is in contact with blood [51]. The BHC herein developed stands out as they benefit from their in-situ viscous injection and further in-vivo ionic gelation. Besides, their good resistance to degradation and retention of mechanical strength when subjected to in-vivo mechanical loading better supports cartilage formation. To monitor the cartilage and bone formation, Viva-CT and histological examination were performed 4 weeks post implantation. The BHC were well integrated with the OC surrounding tissues within the site defect. It was hypothesised that BHC implantation would result in bone and cartilage-like formation and would act synergistically to improve $O C$ tissue regeneration. The grey colour displayed in the Control group showed the presence of the fissure which pertains to the critical defect induced in the rabbit's knee. No red signal (hard or bone-like tissue) was found in the Control group. In the BHC group, new bone formation was evidenced by the red signal at the bottom region in the Viva-CT images. Same images display an upper green region which refers either to cartilage-like or partially degraded hydrogel. Histological data demonstrated the presence of the loose tissue clearly seen in the Control group thorough the critical defect, top to bottom. The occurrence of vertical fissures from top to in-depth subchondral region in the Control group has been reported in the literature by Shapiro et al. [52] as a unique characteristic of cartilage degeneration. Therefore, cartilage fibrillation, proteoglycans loss and cell death lead to defective tissue formation without the capability for subsequent repair $[35,53]$. The BHC group showed in the bottom part of the site defect newly formed subchondral bone with the presence of obvious bony islets in the subchondral region. Even with the reduced bone-tissue formation 4 weeks after implantation, the existence of woven bone islets in subchondral bone is a phenomenon commonly seen in early bone repair and is critical for fixing the implant [51,54]. The new bone ingrowth is restricted to the bone-like layer co-localised with the LAGG-HAp 20\%. Even 4 weeks after implantation, some material was not fully degraded although it may play a crucial role in providing mechanical support for cartilaginous tissue formation on the top surface of the defect.

Tissue-containing chondrocytes in the top layer was indicated by the intense signals of proteoglycan production. Although, neocartilage tissue and subchondral bone newly formed at the implant site were well integrated within surrounding tissues, what was often observed in the subchondral region was some tissue infiltration with partially degraded hydrogel. Bone-like tissue infiltration started from the defect margins towards the centre. Therefore, LAGG-HAp 20\% seems to be biomimetic of subchondral tissue prompting new bone formation. In summary, at 4 weeks postimplantation, the BHC group showed better cartilage-like and bone-like tissue formation than that in the Control group. Additionally, BHC had direct bonding with host tissues, cartilage and bone. Therefore, the newly formed cartilage and the yet scarce bone formation were very similar to the native tissues. The well-integrated BHC structure within the surrounding tissues improved the OC repair thanks to the high mechanical strength of the BHC which supported new tissue formation while facilitating BHC fixation and integration.

The combination of multilayered constructs, such as BHC, with biomimetics (i.e. cells, growth factors, drugs etc.) seems a very 
promising strategy for facilitating regeneration of complex tissues. $\mathrm{OC}$ regeneration also benefits when using of a variety number of soluble cues which can target specific pathways involved in the $\mathrm{OC}$ regeneration $[55,56]$. Therefore, our findings are consistent with those of Frenkel et al. [57] as used for biphasic scaffolds: HAChitosan or Collagen type I as cartilaginous layer and PDLLA-HAp as osteogenic layer, without any biotic element to repair rabbit's OC defects. The bilayered scaffold was fully degraded 24 weeks after implantation and OC tissue repair was achieved. A similar study which investigated the benefit of presence/absence of biotic elements, either cells or biomolecules, in biphasic constructs was reported by Sosio et al. [58] Another study developed by Deng et al. [59] reported the simultaneous regeneration of both tissues, cartilage and subchondral bone, with bioactive ion-scaffolds with synergistic effects for OC regeneration. Biphasic acellular systems showed superior regeneration of OC defects. However, we critically discuss here the need for increasing time implantation up to 4 weeks. Long-term in-vivo studies need to be undertaken to confirm the functional hyaline cartilage formation and the effective bone-tissue formation [56]. In line with our suggestion, Li et al. [35] reported that both acellular and cellular bilayered constructs were able to indistinguishable bond to the surrounding tissues, after 12 weeks post-implantation. The defect site presented similar morphology for both groups, acellular and cellular construct, with extensive chondrogenesis and osteogenesis.

\section{Conclusion}

The acellular bilayered hydrogel composites (BHC) were designed and fabricated presenting an interconnected hierarchical structure composed of a chondral and subchondral bone-like layer with integration of both. The superior mechanical strength of the BHC derives from their unique design. GG-based layers and reinforcement of the bone-like layer with the finest ceramic (HAp) creates a resilient bilayered construct with an interfacial region capable not only of integrating dissimilar zones but also of providing good stability over degradation. Additionally, BHC were biomimetic towards bone formation. When subjected to in-situ mechanical loading in OC living tissue, the BHC will be capable of bearing a temporary load while neo-tissue was formed. The nontoxicity as well as good tissue compatibility brings an opportunity to create cell-laden constructs as a robust system for OC regeneration. When subcutaneously implanted in mice, BHC induces a weak foreign body reaction. BHC can be seen as promising constructs to regenerate defective $\mathrm{OC}$ tissues. Indeed, $\mathrm{BHC}$ showed good integration with surrounding tissues, supporting cartilage and bone-like tissue formation, 4 weeks after implantation in orthotopic knee model. In summary, this study demonstrates the feasibility of the $\mathrm{BHC}$ as OC substitutes with unique features to be exploited for OC regeneration. Combinatorial approaches by the use of biotic factors are certainly foreseen. Bone marrow technique and incorporation of sustained release factors can generate justifiable interest in creating acellular multifactorial constructs.

\section{Conflict of interest statement}

The authors declare that there is no conflict of interests regarding the publication of this paper.

\section{Acknowledgments}

This material is based on works supported by the Portuguese Foundation for Science and Technology (FCT) under the OsteoCart project (PTDC/CTM-BPC/115977/2009) and for the M-ERA-NET/0001/2014 project. The authors are grateful to Teresa Oliveira for the assistance with histological studies. DR Pereira acknowledges the FCT for the individual grant (SFRH/BD/81356/2011) and JM Oliveira also thanks the FCT for the funds provided under the program Investigator FTC 2012 and 2015 (IF/00423/2012 and IF/01285/2015).

\section{Appendix A. Supplementary data}

Supplementary data associated with this article can be found, in the online version, at doi:10.1016/j.apmt.2018.06.005.

\section{References}

[1] G.A. Ateshian, V.C. Mow, Friction, lubrication, and wear of articular cartilage and diarthrodial joints, in: V.C. Mow, R. Huiskes (Eds.), Basic Orthopaedic Biomechanics and Mechano-biology, 3rd ed., Lippincott Williams \& Wilkins, 2005, pp. 447-494.

[2] E.B. Hunziker, L.C. Rosenberg, Repair of partial-thickness defects in articular cartilage: cell recruitment from the synovial membrane, J. Bone Joint Surg. 78 A (5) (1996) 721-733.

[3] J.C. Erhart-Hledik, J. Favre, J.L. Asay, R.L. Smith, N.J. Giori, A. Mündermann, T.P. Andriacchi, A relationship between mechanically-induced changes in serum cartilage oligomeric matrix protein (COMP) and changes in cartilage thickness after 5 years, Osteoarthritis Cartilage 20 (11) (2012) 1309-1315.

[4] R.K. Sanders, J.R. Crim, Osteochondral injuries, Semin Ultrasound CT MRI 22 (4) (2001) 352-370.

[5] J. Espregueira-Mendes, H. Pereira, N. Sevivas, P. Varanda, M.V. Silva, A. Monteiro, J.M. Oliveira, R.L. Reis, Osteochondral transplantation using autografts from the upper tibio-fibular joint for the treatment of knee cartilage lesions, Knee Surg. Sports Traumatol. Arthrosc. 20 (6) (2012) $1136-1142$.

[6] A.C. Kuo, J.J. Rodrigo, A.H. Reddi, S. Curtiss, E. Grotkopp, M. Chiu, Microfracture and bone morphogenetic protein 7 (BMP-7) synergistically stimulate articular cartilage repair, Osteoarthritis Cartilage 14 (11) (2006) 1126-1135.

[7] P.S.J.M. Bouwmeester, R. Kuijer, G.N. Homminga, S.K. Bulstra, R.G.T. Geesink, A retrospective analysis of two independent prospective cartilage repair studies: autogenous perichondrial grafting versus subchondral drilling 10 years post-surgery, J. Orthop. Res. 20 (2) (2002) 267-273.

[8] R.E. Outerbridge, The etiology of chondromalacia patellae, J. Bone Joint Surg. Br. 43B (1961) 752-757

[9] R.E. Outerbridge, Further studies on the etiology of chondromalacia patellae, J. Bone Joint Surg. Br. 46 (1964) 179-190.

[10] H.K. Outerbridge, A.R. Outerbridge, R.E. Outerbridge, The use of a lateral patellar autologous graft for the repair of a large osteochondral defect in the knee, J. Bone Joint Surg. Am. 77 (1) (1995) 65-72.

[11] J.E. Browne, T.P. Branch, Surgical alternatives for treatment of articular cartilage lesions, J. Am. Acad. Orthop. Surg. 8 (3) (2000) 180-189.

[12] P. Ellender, A. Gomoll, T. Minas, Autologous chondrocyte implantation for osteochondritis dissecans in the knee, Oper. Tech. Sports Med. 16 (2) (2008) 89-96.

[13] S.E. Domayer, S. Apprich, D. Stelzeneder, C. Hirschfeld, M. Sokolowski, C. Kronnerwetter, C. Chiari, R. Windhager, S. Trattnig, Cartilage repair of the ankle: first results of T2 mapping at 7.0 T after microfracture and matrix associated autologous cartilage transplantation, Osteoarthritis Cartilage 20 (8) (2012) 829-836

[14] Š. Zbýň, D. Stelzeneder, G.H. Welsch, L.L. Negrin, V. Juras, M.E. Mayerhoefer, P. Szomolanyi, W. Bogner, S.E. Domayer, M. Weber, S. Trattnig, Evaluation of native hyaline cartilage and repair tissue after two cartilage repair surgery techniques with 23Na MR imaging at $7 \mathrm{~T}$ : initial experience, Osteoarthritis Cartilage 20 (8) (2012) 837-845

[15] H. Mullett, J.G. Kennedy, W. Quinlan, Subchondral talar cyst following open reduction and internal fixation of an ankle fracture, Foot Ankle Surg. 5 (3) (1999) 147-149.

[16] J. Chen, H. Chen, P. Li, H. Diao, S. Zhu, L. Dong, R. Wang, T. Guo, J. Zhao, J. Zhang, Simultaneous regeneration of articular cartilage and subchondral bone in vivo using MSCs induced by a spatially controlled gene delivery system in bilayered integrated scaffolds, Biomaterials 32 (21) (2011) 4793-4805.

[17] A. Gomoll, H. Madry, G. Knutsen, N. Dijk, R. Seil, M. Brittberg, E. Kon, The subchondral bone in articular cartilage repair: current problems in the surgical management, Knee Surg. Sports Traumatol. Arthrosc. 18 (4) (2010) 434-447.

[18] Y. Wang, H. Meng, X. Yuan, J. Peng, Q. Guo, S. Lu, A. Wang, Fabrication and in vitro evaluation of an articular cartilage extracellular matrix-hydroxyapatite bilayered scaffold with low permeability for interface tissue engineering, Biomed. Eng. Online 13 (2014) 80

[19] M. Naebe, K. Shirvanimoghaddam, Functionally graded materials: a review of fabrication and properties, Appl. Mater. Today 5 (2016) 223-245.

[20] J.M. Oliveira, M.T. Rodrigues, S.S. Silva, P.B. Malafaya, M.E. Gomes, C.A. Viegas, I.R. Dias, J.T. Azevedo, J.F. Mano, R.L. Reis, Novel hydroxyapatite/chitosan bilayered scaffold for osteochondral tissue-engineering applications: scaffold design and its performance when seeded with goat bone marrow stromal cells, Biomaterials 27 (36) (2006) 6123-6137. 
[21] A.M.J. Getgood, S.J. Kew, R. Brooks, H. Aberman, T. Simon, A.K. Lynn, N. Rushton, Evaluation of early-stage osteochondral defect repair using a biphasic scaffold based on a collagen-glycosaminoglycan biopolymer in a caprine model, Knee 19 (4) (2012) 422-430.

[22] X. Guo, H. Park, G. Liu, W. Liu, Y. Cao, Y. Tabata, F.K. Kasper, A.G. Mikos, In vitro generation of an osteochondral construct using injectable hydrogel composites encapsulating rabbit marrow mesenchymal stem cells, Biomaterials 30 (14) (2009) 2741-2752.

[23] M. Kim, S.E. Kim, S.S. Kang, Y.H. Kim, G. Tae, The use of de-differentiated chondrocytes delivered by a heparin-based hydrogel to regenerate cartilage in partial-thickness defects, Biomaterials 32 (31) (2011) 7883-7896.

[24] X. Guo, H. Park, S. Young, J.D. Kretlow, J.J. van den Beucken, L.S. Baggett, Y. Tabata, F.K. Kasper, A.G. Mikos, J.A. Jansen, Repair of osteochondral defects with biodegradable hydrogel composites encapsulating marrow mesenchymal stem cells in a rabbit model, Acta Biomater. 6 (1) (2010) 39-47.

[25] T.A. Holland, E.W.H. Bodde, V.M.J.I. Cuijpers, L.S. Baggett, Y. Tabata, A.G. Mikos, J.A. Jansen, Degradable hydrogel scaffolds for in vivo delivery of single and dual growth factors in cartilage repair, Osteoarthritis Cartilage 15 (2) (2007) 187-197.

[26] H. Grasdalen, O. Smidsrød, Gelation of gellan gum, Carbohydr. Polym. 7 (5) (1987) 371-393.

[27] P.-E. Jansson, B. Lindberg, P.A. Sandford, Structural studies of gellan gum, an extracellular polysaccharide elaborated by Pseudomonas elodea, Carbohydr. Res. 124 (1) (1983) 135-139.

[28] J.T. Oliveira, L. Martins, R. Picciochi, P.B. Malafaya, R.A. Sousa, N.M. Neves, J.F. Mano, R.L. Reis, Gellan gum: a new biomaterial for cartilage tissue engineering applications, J. Biomed. Mater. Res. A 93 (3) (2010) 852-863.

[29] J.T. Oliveira, L.S. Gardel, T. Rada, L. Martins, M.E. Gomes, R.L. Reis, Injectable gellan gum hydrogels with autologous cells for the treatment of rabbit articular cartilage defects, J. Orthop. Res. 28 (9) (2010) 1193-1199.

[30] J.T. Oliveira, T.C. Santos, L. Martins, R. Picciochi, A.P. Marques, A.G. Castro, N.M. Neves, J.F. Mano, R.L. Reis, Gellan gum injectable hydrogels for cartilage tissue engineering applications: in vitro studies and preliminary in vivo evaluation, Tissue Eng. Part A 16 (1) (2010) 343-353.

[31] J. Silva-Correia, V. Miranda-Goncalves, A.J. Salgado, N. Sousa, J.M. Oliveira, R.M. Reis, R.L. Reis, Angiogenic potential of gellan gum-based hydrogels for application in nucleus pulposus regeneration: in vivo study, Tissue Eng.: Part A $18(11-12)(2012) 1203-1212$.

[32] D.A. Walsh, D.F. McWilliams, M.J. Turley, M.R. Dixon, R.E. Fransés, P.I. Mapp, D. Wilson, Angiogenesis and nerve growth factor at the osteochondral junction in rheumatoid arthritis and osteoarthritis, Rheumatology 49 (10) (2010) 1852-1861.

[33] T. Kokubo, H. Kushitani, S. Sakka, T. Kitsugi, T. Yamamuro, Solutions able to reproduce in vivo surface-structure changes in bioactive glass-ceramic A-W, J. Biomed. Mater. Res. 24 (6) (1990) 721-734.

[34] S. Koutsopoulos, Synthesis and characterization of hydroxyapatite crystals: a review study on the analytical methods, J. Biomed. Mater. Res. 62 (4) (2002) 600-612.

[35] X. Li, Y. Li, Y. Zuo, D. Qu, Y. Liu, T. Chen, N. Jiang, H. Li, J. Li, Osteogenesis and chondrogenesis of biomimetic integrated porous PVA/gel/V-n-HA/pa6 scaffolds and BMSCs construct in repair of articular osteochondral defect, J. Biomed. Mater. Res. A 103 (10) (2015) 3226-3236.

[36] L.-P. Yan, J. Silva-Correia, M.B. Oliveira, C. Vilela, H. Pereira, R.A. Sousa, J.F. Mano, A.L. Oliveira, J.M. Oliveira, R.L. Reis, Bilayered silk/silk-nanoCaP scaffolds for osteochondral tissue engineering: In vitro and in vivo assessment of biological performance, Acta Biomater. 12 (2015) 227-241.

[37] J. Lam, S. Lu, V.V. Meretoja, Y. Tabata, A.G. Mikos, F.K. Kasper, Generation of osteochondral tissue constructs with chondrogenically and osteogenically predifferentiated mesenchymal stem cells encapsulated in bilayered hydrogels, Acta Biomater. 10 (3) (2014) 1112-1123.

[38] M. Bartnikowski, R.A. Akkineni, M. Gelinsky, A.M. Woodruff, J.T. Klein, A hydrogel model incorporating 3D-plotted hydroxyapatite for osteochondral tissue engineering, Materials 9 (4) (2016) 285

[39] K. Schutz, F. Despang, A. Lode, M. Gelinsky, Cell-laden biphasic scaffolds with anisotropic structure for the regeneration of osteochondral tissue, J. Tissue Eng. Regen. Med. 10 (5) (2016) 404-417.
[40] T. Li, X. Song, C. Weng, X. Wang, L. Sun, X. Gong, L. Yang, C. Chen, Self-crosslinking and injectable chondroitin sulfate/pullulan hydrogel for cartilage tissue engineering, Appl. Mater. Today 10 (2018) 173-183.

[41] D.R. Pereira, R.F. Canadas, J.S. Correia, A.P. Marques, R.L. Reis, J.M. Oliveira, Gellan gum-based hydrogel bilayered scaffolds for osteochondral tissue engineering, Key Eng. Mater. 587 (2014) 255-260.

[42] S. Agnello, L. Gasperini, J.F. Mano, G. Pitarresi, F.S. Palumbo, R.L. Reis, G. Giammona, Synthesis, mechanical and thermal rheological properties of new gellan gum derivatives, Int. J. Biol. Macromol. 98 (2017) 646-653.

[43] J. Silva-Correia, A. Gloria, M.B. Oliveira, J.F. Mano, J.M. Oliveira, L. Ambrosio, R.L. Reis, Rheological and mechanical properties of acellular and cell-laden methacrylated gellan gum hydrogels, J. Biomed. Mater. Res. A 101 (12) (2013) 3438-3446.

[44] M. Vallet-Regi, Revisiting ceramics for medical applications, Dalton Trans. (44) (2006) 5211-5220.

[45] D.R. Pereira, J. Silva-Correia, S.G. Caridade, J.T. Oliveira, R.A. Sousa, A.J. Salgado, J.M. Oliveira, J.F. Mano, N. Sousa, R.L. Reis, Development of gellan gum-based microparticles/hydrogel matrices for application in the intervertebral disc regeneration, Tissue Eng. Part C: Methods 17 (10) (2011) 961-972.

[46] J.R. Jones, Review of bioactive glass: from Hench to hybrids, Acta Biomater. 9 (1) (2013) 4457-4486

[47] T. Kawasaki, Hydroxyapatite as a liquid chromatographic packing, J. Chromatogr. A 544 (1991) 147-184.

[48] J. Christoffersen, M.R. Christoffersen, R. Larsen, I.J. Møller, Regeneration by surface-coating of bone char used for defluoridation of water, Water Res. 25 (2) (1991) 227-229.

[49] B. Marelli, C.E. Ghezzi, D. Mohn, W.J. Stark, J.E. Barralet, A.R. Boccaccini, S.N. Nazhat, Accelerated mineralization of dense collagen-nano bioactive glass hybrid gels increases scaffold stiffness and regulates osteoblastic function, Biomaterials 32 (34) (2011) 8915-8926.

[50] B. Marelli, C.E. Ghezzi, J.E. Barralet, A.R. Boccaccini, S.N. Nazhat, Three-dimensional mineralization of dense nanofibrillar collagen-bioglass hybrid scaffolds, Biomacromolecules 11 (6) (2010) 1470-1479.

[51] N. Joshi, M. Reverte-Vinaixa, E.W. Diaz-Ferreiro, R. Dominguez-Oronoz, Synthetic resorbable scaffolds for the treatment of isolated patellofemoral cartilage defects in young patients: magnetic resonance imaging and clinical evaluation, Am. J. Sports Med. 40 (6) (2012) 1289-1295.

[52] F. Shapiro, S. Koide, M.J. Glimcher, Cell origin and differentiation in the repair of full-thickness defects of articular cartilage, J. Bone Joint Surg. Am. 75 (4) (1993) 532-553.

[53] D. Qu, J. Li, Y. Li, Y. Gao, Y. Zuo, Y. Hsu, J. Hu, Angiogenesis and osteogenesis enhanced by bFGF ex vivo gene therapy for bone tissue engineering in reconstruction of calvarial defects, J. Biomed. Mater. Res. A 96 (3) (2011) $543-551$.

[54] M. Yamamoto, Y. Takahashi, Y. Tabata, Enhanced bone regeneration at a segmental bone defect by controlled release of bone morphogenetic protein-2 from a biodegradable hydrogel, Tissue Eng. 12 (5) (2006) 1305-1311.

[55] E.B. Hunziker, I.M. Driesang, Functional barrier principle for growth-factor-based articular cartilage repair, Osteoarthritis Cartilage 11 (5) (2003) 320-327.

[56] S. Lu, J. Lam, J.E. Trachtenberg, E.J. Lee, H. Seyednejad, J.J. van den Beucken, Y. Tabata, M.E. Wong, J.A. Jansen, A.G. Mikos, F.K. Kasper, Dual growth factor delivery from bilayered, biodegradable hydrogel composites for spatially-guided osteochondral tissue repair, Biomaterials (31) (2014) 8829-8839.

[57] S.R. Frenkel, G. Bradica, J.H. Brekke, S.M. Goldman, K. Ieska, P. Issack, M.R. Bong, H. Tian, J. Gokhale, R.D. Coutts, R.T. Kronengold, Regeneration of articular cartilage-evaluation of osteochondral defect repair in the rabbit using multiphasic implants, Osteoarthritis Cartilage 13 (9) (2005) 798-807.

[58] C. Sosio, A. Di Giancamillo, D. Deponti, F. Gervaso, F. Scalera, M. Melato, M. Campagnol, F. Boschetti, A. Nonis, C. Domeneghini, A. Sannino, G.M. Peretti, Osteochondral repair by a novel interconnecting collagen-hydroxyapatite substitute: a large-animal study, Tissue Eng. Part A 21 (3-4) (2015) 704-715.

[59] C. Deng, Q. Yang, X. Sun, L. Chen, C. Feng, J. Chang, C. Wu, Bioactive scaffolds with $\mathrm{Li}$ and $\mathrm{Si}$ ions-synergistic effects for osteochondral defects regeneration, Appl. Mater. Today 10 (2018) 203-216. 